\title{
The epidemiology of chronic pain in Canadian men and women between 1994 and 2007: Results from the longitudinal component of the National Population Health Survey
}

\author{
Michelle L Reitsma RN MSc ${ }^{1}$, Joan E Tranmer RN PhD², \\ Diane M Buchanan RN PhD ${ }^{2}$, Elizabeth G VanDenKerkhof RN DrPH ${ }^{1,2}$
}

\begin{abstract}
ML Reitsma, JE Tranmer, DM Buchanan, EG VanDenKerkhof. The epidemiology of chronic pain in Canadian men and women between 1994 and 2007: Results from the longitudinal component of the National Population Health Survey. Pain Res Manage 2012;17(3):166-172.
\end{abstract}

BACKGROUND: The epidemiology of chronic pain is poorly understood due to a paucity of longitudinal studies limiting the ability to develop prevention strategies for a condition resistant to many current therapies. OBJECTIVES: To identify the incidence of and sociodemographic risk factors for chronic pain in Canadian women and men over a 12-year period.

METHODS: Using data from the National Population Health Survey, individuals who developed chronic pain, defined as the presence of "usual pain" were identified. The cumulative incidence of chronic pain was calculated separately for men and women followed from 1994 to 2007. Biannual incidence and prevalence estimates of chronic pain were calculated during the same time period. Logistic regression analysis was used to examine predictors of chronic pain in men and women.

RESULTS: The cumulative incidence over the 12 -year period was $35.6 \%$ (women 39.0\%; men 32.2\%). Women had a higher biannual prevalence, but not incidence, of chronic pain compared with men. In women, being older, having lower education and being widowed, separated or divorced, increased the risk of chronic pain. There were no sociodemographic risk factors for chronic pain in men.

CONCLUSION: Women had a higher prevalence - but not incidence of chronic pain compared with men, indicative of longer duration of illness in women. Risk factors also differed according to sex, supporting current literature reporting potentially different mechanisms for men and women. A better understanding of risk factors is necessary to develop populationbased preventive interventions. The former can only be achieved with population-based, longitudinal studies.

Key Words: Chronic pain; General population; Incidence; Predictors; Sociodemographic factors

$\mathrm{T}$ he prevalence of nonspecific chronic pain is estimated to range from $2 \%$ to $55 \%$ in the general population $(1,2)$. Based on results from the 1994/1995 National Population Health Survey (NPHS), approximately $17 \%$ of Canadians (corresponding to 3.9 million adults [15 years of age or older]) reported having chronic pain or some discomfort (3). Furthermore, in North America alone, chronic pain costs approximately $\$ 165$ billion/year (approximately $\$ 15$ billion/ year in Canada) in health care, disability and litigation costs (4).

While prevalence estimates provide insight into the burden of chronic pain in Canada, few studies have examined the risk or incidence (ie, new cases) of chronic pain. A thorough review of the literature produced only four prospective studies, one of which was conducted in Canada. However, the Canadian study was not
L'épidémiologie de la douleur chronique chez les Canadiens et les Canadiennes entre 1994 et 2007 : les résultats du volet longitudinal de l'Enquête nationale sur la santé de la population

HISTORIQUE : La compréhension de l'épidémiologie de la douleur chronique est limitée par le peu d'études cliniques, ce qui réduit la capacité d'élaborer des stratégies de prévention d'un problème qui résiste à de nombreux traitements.

OBJECTIFS : Déterminer l'incidence et les facteurs de risque sociodémographiques de la douleur chronique chez les Canadiennes et les Canadiens sur une période de 12 ans.

MÉTHODOLOGIE : À l'aide de données tirées de l'Enquête nationale sur la santé de la population, les chercheurs ont repéré les personnes qui se mettent à souffrir de douleur chronique, définie comme la présence d'une « douleur habituelle». Ils ont calculé l'incidence cumulative de douleur chronique séparément pour les hommes et pour les femmes, qui ont été suivis de 1994 à 2007. Ils ont calculé l'incidence semestrielle et les évaluations de prévalence de douleur chronique pendant la même période. L'analyse de régression logistique a permis d'examiner les prédicteurs de douleur chronique chez les hommes et chez les femmes.

RÉSULTATS : L'incidence cumulative sur la période de 12 ans s'élevait à 35,6 \% (femmes 39,0 \%; hommes 32,2\%). Les femmes présentaient une plus forte prévalence semestrielle, mais pas une plus forte incidence de douleur chronique par rapport aux hommes. Chez les femmes, le fait d'être plus âgées, d'être moins scolariséeset d'être veuves, séparées ou divorcées accroissait le risque de douleur chronique. Il n'y avait pas de facteurs de risque sociodémographiques de douleur chronique chez les hommes.

CONCLUSION : Les femmes avaient une plus forte prévalence, mais pas une plus forte incidence de douleur chronique par rapport aux hommes, ce qui est indicatif d'une durée plus longue chez les femmes. Les facteurs de risque différaient également selon le sexe, ce qui étaye les publications actuelles faisant état de mécanismes potentiellement différents chez les hommes et chez les femmes. Il faudra mieux comprendre les facteurs de risque pour élaborer des interventions préventives en population. On y parviendra seulement avec des études longitudinales en population.

representative of the general population because it only included individuals who were employed at baseline (5). Of the three remaining prospective studies (6-8), the largest was in Denmark (6), where $10.7 \%$ of 2649 individuals reported chronic pain over a sixyear follow-up period. In the American study (7), 441 (19\%) of the 2324 individuals who were pain free at baseline reported chronic pain eight years later. In the study from the United Kingdom (8), $33.3 \%$ of 1608 individuals reported chronic pain four years later. Average annual incidence rates were 1.8\% (Denmark), 2.4\% (United States) and $8.3 \%$ (Scotland) (6-8). The three prospective studies also provided data on prevalence estimates, which ranged from $15.7 \%$ to $53.8 \%$. In all three studies, prevalence increased between baseline and follow-up. 
Several cross-sectional studies have reported associations between sociodemographic characteristics and chronic pain (2,9-18). Many of these same characteristics were analyzed as potential risk factors in the three prospective studies, including age, sex, race, education, occupation, income, residence and marital status (6-8). Only one prospective study reported older age and lower income as a risk factor (7). Two studies reported sex as a risk factor, with higher incidence rates of chronic pain in women compared with men $(6,7)$. Furthermore, sex differences in the prevalence of chronic pain have been widely reported. A recent literature review (19) reported higher prevalence estimates of the most common types of pain and that women, compared with men, are generally at a greater risk of many types of chronic pain. To date, virtually all studies have grouped men and women together when examining prevalence, incidence and risk factors for chronic pain; however, evidence is emerging that sex differences in pain should be examined separately (19).

Given the paucity of population-based prospective studies examining chronic pain, the purpose of the present study was to identify the incidence and sociodemographic risk factors for chronic pain in the Canadian population. We used the Determinants of Health: The 21st Century Field Model (20) to guide the selection of variables. According to the model, disease or injury (eg, incidence and prevalence of chronic pain) are affected by global factors, which are defined as "community and social environment", "physical environment", and "family and individual environment". For the purpose of the present study, sociodemographic factors were considered as global factors. These global factors indirectly impact on an individual's health and wellbeing. The 21st Century Field Model also includes the three levels of prevention (primary, secondary and tertiary) and indicates the factors that should be targeted at each level (20). The focus of the present study was primary prevention.

\section{METHODS}

\section{Objectives}

The primary objectives of the present study were to identify the incidence of chronic pain over a 12 -year period and to identify sociodemographic factors that increase the risk of experiencing chronic pain 12 years later. The secondary objective was to compare the prevalence and incidence of chronic pain. Analyses for men and women were conducted separately.

The present study was based on the results of seven longitudinal household NPHS cycles conducted by Statistics Canada and includes members of the general Canadian population. The NPHS longitudinal household component (1994/1995, 1996/1997, 1998/1999, 2000/2001, 2002/2003, 2004/2005, 2006/2007) was used in the present study to document chronic pain in Canada between 1994 and 2007. The NPHS began in 1994 as both a cross-sectional and longitudinal survey, and is conducted on an ongoing basis. In 2000/2001, the cross-sectional component of the NPHS became the core part of the Canadian Community Health Survey (CCHS) and the NPHS remained as the longitudinal component (21).

The longitudinal component is collected on selected panel members, one person in each participating household, every second year for twenty years, with limited health-related information collected on the rest of the household (22). Each cycle, information is collected using face to face or computer-assisted telephone interviews (23). In 1994/1995 (cycle 1), most questionnaires were completed in person, with the rest being collected by telephone; however, for all subsequent cycles (1996/1997 to 2006/2007), the majority of the interviews were completed by telephone (23). The NPHS was developed by specialists at Health Canada, Statistics Canada and provincial ministries of health, as well as academic researchers in relevant fields; furthermore, the questionnaire was approved by both expert committees and the Advisory Committee at Statistics Canada (23). It includes information on participants' health status, use of health and medical services, and sociodemographic characteristics (23). The NPHS longitudinal household component excludes individuals living in the territories, in health institutions, in some distant areas, on Crown lands and Indian Reserves, as well as those individuals employed full time in the Canadian Forces (23). The response rates ranged from $77.0 \%$ to $83.6 \%$ (23). Further information on the sample design of the NPHS is available elsewhere (22).

\section{Population and sample}

The longitudinal component of the NPHS included 17,276 individuals at baseline, including children, teenagers and adults (23). Participants were selected using two different sampling techniques: clusters and dwellings (23). The 1991 Census data were used to determine the sample size for each province in the first cycle (1994) (24) and the 1996 Census data were used to create weights that adjusted for nonresponse to ensure consistency among the population sampled in 1994/1995 (the reference year) (24). Further information on how participants were sampled for the NPHS is available elsewhere (23).

Adults age 25 years of age or older were included in the present study. Participants had to have a full response set to be included in the sample. To be considered full response meant that each participant had to have either completed each cycle, were deceased or were institutionalized (24).

\section{Incidence sample}

Incidence of chronic pain was calculated using cycles 2 to 7 (1996/1997, 1998/1999, 2000/2001, 2002/2003, 2004/2005 and 2006/2007) of the longitudinal component of the NPHS. Incidence refers to the number of new cases of chronic pain in a specified time period (25). The incidence samples included participants who were 25 years of age or older at baseline (1994/1995) and who did not report chronic pain in any previous cycle (25). Combining these individual incidence rates gives the total number of new cases of chronic pain, which is referred to as the cumulative incidence. Cumulative incidence was calculated by summing all of the biennial incidence rates of chronic pain.

\section{Prevalence sample}

Prevalence was also calculated in all seven cycles (1994/1995, 1996/1997, 1998/1999, 2000/2001, 2002/2003, 2004/2005 and 2006/2007) of the longitudinal component of the NPHS. The prevalence samples included participants 25 years of age or older at baseline (1994/1995) regardless of whether they reported chronic pain in previous cycles. Prevalence is the number of people reporting chronic pain at a selected time point (25).

\section{Predictive sample}

The sample used to calculate predictors of chronic pain included participants who were 25 years of age or older at baseline (1994/1995). Incidence for this analysis was defined as participants who were free of pain at baseline (1994/1995) and reported pain in the last cycle (2006/2007)

\section{Variables}

Outcome variables: Participants were asked to report on the presence of 'usual pain' using the question "Are you usually free of pain or discomfort?" (26). Individuals were considered to have chronic pain if they answered "no" to being usually free of pain. If participants answered "yes" to being usually free of pain, they were identified as not having chronic pain. In the present study, the prevalence and incidence of chronic pain was split into two main groups based on the primary pain free question: no pain and pain. These questions came from the NPHS, CCHS and Health Utility Index, and are considered to be valid questions to identify chronic pain (27-29).

Independent variables: These variables were measured using various questions and derived variables from the NPHS. Sex, marital status, province of residence and employment status data were collected directly from the NPHS. Sex consisted of two categories: male and female. The marital status variable was recoded into four categories: currently married, common-law/living with a partner, single (never married), and widowed/separated/divorced. Province consisted of the 
TABLE 1

Characteristics of respondents 25 years of age or older, and pain free at baseline in the National Population Health Survey

\begin{tabular}{|c|c|c|c|}
\hline & Women & Men & Total \\
\hline \multicolumn{4}{|l|}{ Age, years } \\
\hline 25-39 & 41.2 & 42.1 & 41.7 \\
\hline $40-54$ & 28.9 & 31.7 & 30.3 \\
\hline $55-69$ & 18.6 & 18.0 & 18.3 \\
\hline$\geq 70$ & 11.3 & 8.2 & 9.8 \\
\hline \multicolumn{4}{|l|}{ Education } \\
\hline Postsecondary graduation & 35.6 & 40.4 & 38.1 \\
\hline Some postsecondary & 23.8 & 23.1 & 23.4 \\
\hline Secondary school graduation & 18.6 & 15.1 & 16.8 \\
\hline Less than secondary school graduation & 22.0 & 21.4 & 21.7 \\
\hline \multicolumn{4}{|l|}{ Marital status } \\
\hline Currently married & 63.7 & 70.3 & 67.1 \\
\hline Common law/living with a partner & 6.9 & 7.6 & 7.3 \\
\hline Single (never married) & 9.6 & 13.9 & 11.8 \\
\hline Widowed/separated/divorced & 19.9 & 8.1 & 13.9 \\
\hline \multicolumn{4}{|l|}{ Race } \\
\hline White & 91.0 & 91.6 & 91.3 \\
\hline Black & 1.2 & 2.4 & 1.8 \\
\hline Chinese & 2.6 & 1.9 & 2.3 \\
\hline Aboriginal Peoples of North America & 0.3 & 0.6 & 0.5 \\
\hline Other & 4.8 & 3.5 & 4.2 \\
\hline \multicolumn{4}{|l|}{ Province } \\
\hline British Columbia & 13.0 & 13.9 & 13.4 \\
\hline Alberta & 9.1 & 9.4 & 9.3 \\
\hline Saskatchewan & 3.3 & 3.3 & 3.3 \\
\hline Manitoba & 3.7 & 3.6 & 3.7 \\
\hline Ontario & 38.0 & 38.2 & 38.1 \\
\hline Quebec & 24.7 & 23.6 & 24.1 \\
\hline New Brunswick & 2.5 & 2.6 & 2.6 \\
\hline Nova Scotia & 3.1 & 3.0 & 3.1 \\
\hline Prince Edward Island & 0.5 & 0.4 & 0.5 \\
\hline Newfoundland and Labrador & 2.2 & 2.0 & 2.1 \\
\hline \multicolumn{4}{|l|}{ Area of residence } \\
\hline Urban & 84.3 & 81.1 & 82.7 \\
\hline Rural & 15.7 & 18.9 & 17.3 \\
\hline \multicolumn{4}{|l|}{ Income } \\
\hline Highest & 16.2 & 21.6 & 18.9 \\
\hline Upper middle & 38.1 & 39.8 & 39.0 \\
\hline Lower middle & 28.6 & 27.6 & 28.1 \\
\hline Lowest & 17.1 & 11.1 & 14.1 \\
\hline \multicolumn{4}{|l|}{ Main activity } \\
\hline Working for pay or profit & 24.9 & 61.4 & 43.4 \\
\hline Caring for family & 26.6 & 1.3 & 13.8 \\
\hline Caring for family/working for pay or profit & 26.9 & 13.0 & 19.8 \\
\hline Looking for work & 1.6 & 3.9 & 2.7 \\
\hline Retired & 16.3 & 16.0 & 16.2 \\
\hline $\begin{array}{l}\text { Other (Includes going to school and } \\
\text { recovering from illness/disability)* }\end{array}$ & 3.7 & 4.6 & 4.1 \\
\hline
\end{tabular}

Data presented as \%. Results were weighted to the Canadian population and are representative of most of the population

10 provinces (the territories were not included). Employment status was determined through the question asking about the participant's main activities. This variable was recoded into six categories: working for pay or profit, caring for family, caring for family/working for pay or profit, looking for work, retired and other.

Age, education, race, area of residence, and income were derived from Statistics Canada data. The derived age variable was recoded into the following four age groups: 25 to 39,40 to 54,55 to 69 years of age, and 70 years or age or older. The derived education variable consisted of four categories: less than secondary school graduation; secondary school graduation; some postsecondary; and postsecondary graduation. Race was based on a derived variable that was further recoded into White, Black, Chinese, Aboriginal Peoples of North America, and other due to small numbers in many of the race categories in the original classification, in particular, after stratifying according to sex and chronic pain status. Residence was based on a derived variable classified into urban or rural. For income adequacy, the derived variable that was used also accounted for household size. This variable consisted of four categories: lowest income, lower middle income, upper middle income and highest income.

\section{Data analysis}

Statistical analyses were performed in The Queen's Research Data Centre (Queen's University [Kingston, Ontario]) using SPSS version 6.13 (IBM Corporation, USA) (for Unix on Solaris) and STATA (STATA Corporation, USA) version 11.0. Frequencies and percentages were used to describe the baseline sociodemographic characteristics of the study population, and to identify the incidence and prevalence of chronic pain at each cycle. Predictors of chronic pain were identified by linking the baseline pain-free sample (1994/1995) with those who developed pain in cycle 7 (2006/2007). Data analysis was completed separately for men and women. $\chi^{2}$ analysis was used to determine whether the sociodemographic factors at baseline (age, education, marital status, race, province, area of residence, income and main activity) were associated with chronic pain (pain/no pain) in cycle 7 (2006/2007). To be included in the multivariate analysis, the independent variable had to be significant at $\mathrm{P}<0.1$ in the bivariate analysis. Logistic regression was used to determine whether baseline sociodemographic factors predicted the presence of chronic pain 12 years later (2006/2007). An F test for joint significance was used to assess the influence of a group of variables on chronic pain while accounting for other independent variables in the regression. $\mathrm{P}<0.05$ indicated that a group of variables had a statistically significant impact on chronic pain. Education and income together influenced chronic pain in women; therefore, only education was included in the logistic regression because it was believed that income, to a certain extent, was based on education. The least significant variable was removed from the logistic regression model one at a time until only significant variables remained in the model. Statistical significance was set at $\mathrm{P}<0.05$. ORs were calculated to assess the strength of the association between the sociodemographic variables and chronic pain, while 95\% CIs were used to determine the precision of the estimates. Bootstrapping was performed to ensure the results were not only significant due to large sample sizes. The weight variable (WT6BLF) was applied to all analyses to adjust for nonresponse. All results were weighted to the Canadian population.

Ethics approval for the present analysis was obtained from Queen's University Health Sciences and Affiliated Teaching Hospitals Research Ethics Board.

\section{Response rates}

\section{RESULTS}

The longitudinal sample consisted of 17,276 participants; however, only 10,992 participants with full responses were included in the present study. The response rates were $>77.0 \%$ for each cycle, with the highest response rate being $92.8 \%$ in cycle 2 (1996/1997) (23).

\section{Characteristics at baseline}

All of these results have been weighted to the population and, therefore, are representative of population rather than sample characteristics. The percentage of women $(49.4 \%)$ and men $(50.6 \%)$ in the population was similar, with $41.7 \%$ of the population between 25 and 39 years of age (Table 1). Thirty-eight per cent completed postsecondary education and $21.7 \%$ did not complete secondary school education. Furthermore, 
$39.0 \%$ were in the upper-middle income level, $43.4 \%$ worked for pay or profit and $16.2 \%$ were retired. The majority of the population were currently married (67.1\%) and Caucasian (91.3\%). Most lived in urban areas $(82.7 \%)$, with $38.1 \%$ of the population living in Ontario.

\section{Incidence of chronic pain}

All incidence samples were pain free in any previous cycle and, therefore, the sample size decreased each cycle. The incidence sample sizes ranged from 3735 participants in 2006/2007 to 6355 participants in 1996/1997. Generally, no significant difference was found between women and men reporting incidence of chronic pain each surveyed year (Figure 1). Incidence for men ranged from $4.8 \%$ (95\% CI 3.5\% to $6.1 \%$ ) in $2006 / 2007$ to $7.1 \%$ (95\% CI $5.9 \%$ to $8.3 \%$ ) in $1996 / 1997$ and in women it ranged from $6.0 \%$ (95\% CI $4.7 \%$ to $7.2 \%$ ) in $2006 / 2007$ to $8.7 \%$ (95\% CI $7.2 \%$ to $10.3 \%$ ) in $2000 / 2001$. The cumulative incidence rate over 12 years was $35.6 \%$ (95\% CI $33.9 \%$ to $37.3 \%$; women $39.0 \%$ [95\% CI $36.6 \%$ to $41.4 \%$ ]; men $32.2 \%$ [95\% CI $29.7 \%$ to $34.7 \%]$ ), with overall incidence rates for individual years ranging from $5.4 \%$ (95\% CI $4.5 \%$ to $6.2 \%$ ) in $2006 / 2007$ to $7.8 \%$ (95\% CI 6.8\% to $8.9 \%$ ) in 1998/1999. The incidence rate in 2007 for the predictive sample was $15.7 \%$ (95\% CI $14.1 \%$ to $17.3 \%$ ) in women and $11.3 \%$ (95\% CI $9.6 \%$ to $13.1 \%$ ) in men.

\section{Sociodemographic predictors of chronic pain}

The longitudinal cohort sample used for the predictive analysis consisted of 2313 men and 2964 women. Due to small cell frequencies, race was further recoded into White and non-White. Age, education and marital status were significant predictors of chronic pain in women (Table 2). Women in the oldest age group (70 years of age or older) had the greatest risk of developing chronic pain (OR $2.24[95 \%$ CI 1.37 to 3.67]). Women in the two middle age groups (40 to 54 years of age OR 1.46 [95\% CI 1.03 to 2.06]; 55 to 69 years of age OR 1.56 [95\% CI 1.09 to 2.24]) were also at a greater risk of developing chronic pain compared with the youngest age group ( 25 to 39 years of age). Compared with women who graduated from postsecondary school, those with less than secondary school (OR 1.46 [95\% CI 1.03 to 2.08]) and some postsecondary (OR 1.48 [95\% CI 1.03 to 2.14]) were at a greater risk of developing chronic pain. Women who were widowed, separated or divorced were more likely to experience chronic pain 12 years later than those who were married (OR 1.61 [95\% CI 1.16 to 2.23]). There were no significant predictors of chronic pain 12 years later in men (Table 2).

\section{Prevalence and incidence of chronic pain}

The prevalence estimates and incidence rates were also compared. Prevalence sample sizes ranged from 6365 participants in 2006/2007 to 8128 participants in $1994 / 1995$. Prevalence estimates were significantly higher than incidence rates at each surveyed year, with the prevalence ranging from $15.3 \%$ (95\% CI $14.2 \%$ to $16.3 \%)$ in $1996 / 1997$ to $19.5 \%$ (95\% CI $18.3 \%$ to $20.7 \%$ ) in $2004 / 2005$. Unlike the incidence results, women had a higher prevalence of chronic pain each surveyed year compared with men (Figure 1). The prevalence of chronic pain in men ranged from a low of $12.1 \%$ (95\% CI $10.6 \%$ to $13.6 \%$ ) in $2000 / 2001$, to a high of $16.1 \%$ (95\% CI $14.4 \%$ to $17.8 \%$ ) in $2004 / 2005$. In women, the prevalence ranged from $16.8 \%$ (95\% CI $15.4 \%$ to $18.3 \%$ ) in $1996 / 1997$, to $22.7 \%$ ( $95 \%$ CI $21.0 \%$ to $24.4 \%$ ) in 2004/2005.

\section{DISCUSSION}

The present study was the first to examine the incidence and predictors of chronic pain, and to compare annual incidence rates and prevalence estimates in the Canadian general population. Yearly incidence rates ranged from $5.4 \%$ to $7.8 \%$, and yearly prevalence rates ranged from $15.3 \%$ to $19.5 \%$. Within sex, the prevalence and incidence did not differ significantly over time. We found no difference in the incidence of chronic pain between men and women, but women had a

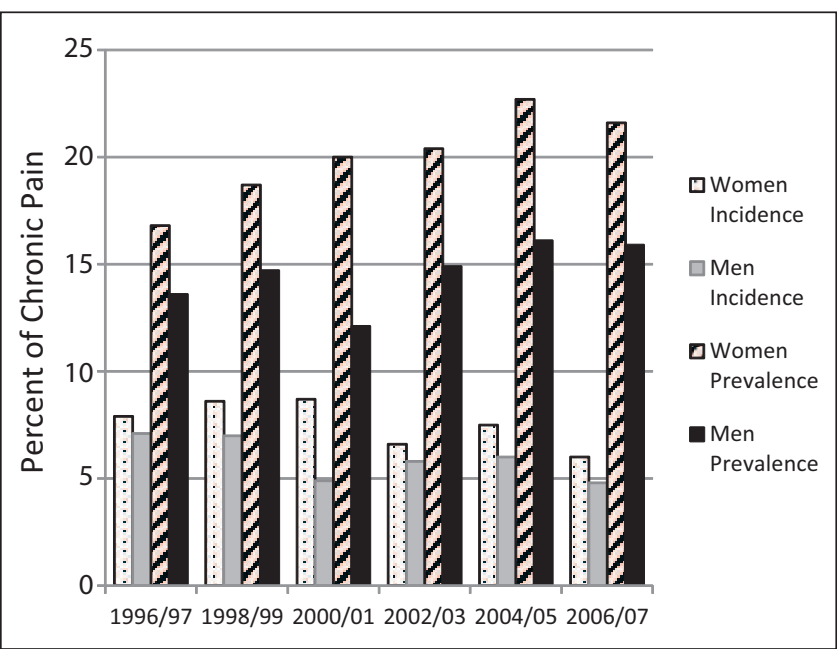

Figure 1) Crude incidence and prevalence of chronic pain in Canadian men and women 25 years of age and older at baseline (1994/1995) at each survey year using longitudinal data from the National Population Health Survey

higher prevalence of chronic pain, indicating that duration of illness is longer in women than men. To our knowledge, this is the first Canadian study to report these findings. Women who were older, with lower education, and widowed, divorced or separated, were at highest risk of chronic pain, whereas this was not the case for men. Our findings for women support the 21st Century Field Model indicating that certain sociodemographic factors (ie, age, education and marital status) may influence chronic pain. This model suggests that disease and injury are affected by global factors (ie, 'community and social environment', 'physical environment' and 'family and individual environment'), which indirectly affect an individual's health and wellbeing (20). In particular, family and individual environment include support from family members (ie, marital status) as impacting disease and injury, in this case, chronic pain (20). This framework also highlights age and education as directly impacting health and well-being (20).

The incidence rate reported in the present study is similar to reports in the literature, which ranged from $1.8 \%$ to $8.3 \%$ per year (6-8). A Danish study reported a higher incidence rate for women (6), but this was not consistent across all studies (8). Furthermore, incidence rates and prevalence estimates have not often been reported together in previous research. The Danish study reported a similar prevalence $(15.7 \%)$ to the present study, but a lower incidence was reported (annual incidence 1.8\%) (6). On the other hand, the Scottish study reported a higher prevalence $(53.8 \%)$ and incidence (average annual incidence: $8.3 \%$ ) of chronic pain compared with the present study (8). Both studies had different follow-up times than our study, with the Danish study having a follow-up of six years (6) and the Scottish study having a follow-up of four years (8). An American study also reported the incidence $(18.8 \%)$ and prevalence $(32.8 \%)$ over an eight-year period (7). Inconsistent duration of chronic pain was used among the three prospective studies, with a shorter duration resulting in higher incidence $(8)$ and prevalence of chronic pain $(7,8)$. These studies also had the smallest sample sizes among the prospective studies $(7,8)$; however, response rates were comparable to previous research (67\% to $83 \%)$.

A previous study has identified sex as a predictor of chronic pain, with women being at greater risk than men (6); however, this is the first study to examine predictors of chronic pain for men versus women and to report different predictors for chronic pain by sex. Reports of the relationship between age and chronic pain are inconsistent. Age was not found to be a risk factor for chronic pain $(6,8)$, but advanced age was found to be positively associated with chronic pain in both sexes (30) 
TABLE 2

Sociodemographic characteristics at baseline (1994/1995) in women and men with chronic pain in 2006/2007 using the longitudinal component of the National Population Health Survey

\begin{tabular}{|c|c|c|c|c|c|c|}
\hline & \multicolumn{3}{|c|}{ Women } & \multicolumn{3}{|c|}{ Men } \\
\hline & \multirow[b]{2}{*}{ Chronic pain, \% } & \multicolumn{2}{|c|}{ OR $(95 \% \mathrm{Cl})$} & \multirow[b]{2}{*}{ Chronic pain, \% } & \multicolumn{2}{|c|}{ OR $(95 \% \mathrm{Cl})$} \\
\hline & & Unadjusted & Adjusted & & Unadjusted & Adjusted \\
\hline \multicolumn{7}{|l|}{ Age-years } \\
\hline 25-39 & 11.9 & 1.00 & 1.00 & 10.5 & 1.00 & \\
\hline $40-54$ & 16.8 & $1.49(1.06-2.10)$ & $1.46(1.03-2.06)$ & 12.3 & $1.2(0.79-1.82)$ & * \\
\hline $55-69$ & 19.1 & $1.74(1.23-2.47)$ & $1.56(1.09-2.24)$ & 12.0 & $1.16(0.72-1.87)$ & \\
\hline$\geq 70$ & 28.4 & $2.93(1.86-4.62)$ & $2.24(1.37-3.67)$ & 10.6 & $1.01(0.28-3.69)$ & \\
\hline \multicolumn{7}{|l|}{ Education } \\
\hline Postsecondary graduation & 12.3 & 1.00 & 1.00 & 10.5 & 1.00 & \\
\hline Some postsecondary & 17.7 & $1.53(1.07-2.17)$ & $1.48(1.03-2.14)$ & 10.6 & $1.01(0.65,1.55)$ & \\
\hline Secondary school graduation & 14.9 & $1.24(0.85-1.80)$ & $1.22(0.84-1.78)$ & 15.7 & $1.59(0.89-2.84)$ & * \\
\hline Less then secondary school graduation & 20.4 & $1.82(1.29-2.57)$ & $1.46(1.03-2.08)$ & 10.7 & $1.03(0.67-1.56)$ & \\
\hline \multicolumn{7}{|l|}{ Marital status } \\
\hline Currently married & 14.0 & 1.00 & 1.00 & 11.7 & 1.00 & \\
\hline Common law/living with a partner & 17.6 & $1.31(0.74-2.32)$ & $1.6(0.89-2.86)$ & 11.9 & $1.02(0.58-1.80)$ & * \\
\hline Single (never married) & 11.0 & $0.76(0.48-1.20)$ & $0.87(0.54-1.42)$ & 9.2 & $0.76(0.43-1.36)$ & \\
\hline Widowed/separated/divorced & 24.3 & $1.97(1.45-2.67)$ & $1.61(1.16-2.23)$ & 11.2 & $0.95(0.55-1.62)$ & \\
\hline \multicolumn{7}{|l|}{ Race } \\
\hline White & 16.4 & 1.00 & * & 11.6 & 1.00 & \\
\hline Nonwhite & 8.2 & $0.46(0.17-1.26)$ & & 8.8 & $0.74(0.32-1.71)$ & * \\
\hline \multicolumn{7}{|l|}{ Province } \\
\hline Manitoba & 22.1 & 1.00 & & 18.7 & 1.00 & \\
\hline New Brunswick & 19.7 & $0.86(0.46-1.62)$ & & 13.7 & $0.69(0.31-1.52)$ & \\
\hline Prince Edward Island & 19.0 & $0.82(0.44-1.52)$ & & 12.8 & $0.64(0.30-1.36)$ & \\
\hline Nova Scotia & 18.4 & $0.79(0.37-1.70)$ & & 12.4 & $0.62(0.28-1.35)$ & \\
\hline Saskatchewan & 18.2 & $0.79(0.40-1.52)$ & * & 11.8 & $0.58(0.25-1.35)$ & \\
\hline Alberta & 18.2 & $0.79(0.41-1.49)$ & & 11.5 & $0.56(0.27-1.17)$ & * \\
\hline Quebec & 17.4 & $0.74(0.39-1.41)$ & & 11.3 & $0.56(0.29-1.05)$ & \\
\hline Ontario & 15.1 & $0.63(0.34-1.14)$ & & 10.9 & $0.53(0.28-1.02)$ & \\
\hline British Columbia & 15.0 & $0.62(0.34-1.15)$ & & 10.1 & $0.49(0.24-0.99)$ & \\
\hline Newfoundland and Labrador & 14.1 & $0.58(0.33-1.02)$ & & 9.1 & $0.43(0.19-0.99)$ & \\
\hline \multicolumn{7}{|l|}{ Area of residence } \\
\hline Urban & 15.6 & 1.00 & * & 11.1 & 1.00 & \\
\hline Rural & 16.0 & $0.97(0.73-1.28)$ & & 12.1 & $0.91(0.62-1.34)$ & * \\
\hline \multicolumn{7}{|l|}{ Income } \\
\hline Highest & 17.0 & 1.00 & & 12.0 & 1.00 & \\
\hline Upper middle & 13.4 & $0.76(0.52-1.1)$ & * & 11.2 & $0.93(0.53-1.62)$ & * \\
\hline Lower middle & 15.4 & 0.89 (0.59-1.34) & & 12.7 & $1.07(0.62-1.83)$ & \\
\hline Lowest & 21.4 & $1.33(0.85-2.08)$ & & 7.6 & $0.6(0.26-1.36)$ & \\
\hline \multicolumn{7}{|l|}{ Main activity } \\
\hline Working for pay or profit & 15.5 & 1.00 & & 11.0 & 1.00 & \\
\hline Caring for family & 14.9 & $0.95(0.67-1.36)$ & & 20.3 & $2.06(0.46-9.17)$ & \\
\hline Caring for family/working for pay or profit & 11.8 & $0.73(0.50-1.06)$ & * & 9.9 & $0.89(0.53-1.48)$ & * \\
\hline Looking for work & 15.0 & $0.96(0.36-2.53)$ & & 11.1 & $1.01(0.46-2.22)$ & \\
\hline Retired & 27.2 & $2.04(1.37-3.03)$ & & 14.3 & $1.36(0.77-2.40)$ & \\
\hline $\begin{array}{l}\text { Other (includes going to school and } \\
\text { recovering from illness/disability) }\end{array}$ & 19.7 & $1.34(0.69-2.58)$ & & 12.1 & $1.11(0.47-2.65)$ & \\
\hline
\end{tabular}

*Not included in multivariate analysis

and in the total population (2,9-14). The cross-sectional component of another study (31) also found the oldest age group ( $\geq 65$ years of age) to report the highest prevalence of chronic pain, with women in the oldest age group reporting the highest levels of chronic pain each surveyed year. Education as a predictor of chronic pain has not often been looked at in the literature; however, education was not found to be a significant predictor of chronic pain $(6,8)$. On the other hand, higher education was associated with lower levels of chronic pain $(9,11,14-17)$, yet no association was found between level of education and chronic pain when sex was taken into account (30). Finally, research examining marital status as a predictor of chronic pain is limited, but it was not found to be a predictor of the incidence of chronic pain $(6,8)$. However, a positive association was found between those who were widowed $(10,16,18)$ or separated/divorced and chronic pain $(11,16,18)$. Being female and widowed were not found to be associated with chronic pain when controlling for other confounding variables (30). 
There are no clear explanations as to why women are at a greater risk of developing chronic pain, and why certain risk factors were found for women and not for men. Other studies support our findings, where women reported higher prevalence estimates of most common types of pain and were generally at a greater risk for many types of chronic pain compared with men (19). Hormones, gender roles and cognitive/affective factors (ie, coping strategies, anxiety and depression) have been identified as possible contributors to the more frequent reports of chronic pain in women (19). A recent population level study found an association between chronic widespread pain and an unhealthy diet in women but not in men (32). Our findings support the emerging evidence that the mechanisms responsible for the development of chronic pain may differ between males and females.

Limitations of the present study include the general nature of the pain question (usual pain) without a specified duration of pain (eg, three months). A variety of chronic pain definitions have been used in the literature, including our definition (27-29). Our findings are similar to a prospective study, which defined chronic pain as lasting at least six months (6), and they are more conservative than prospective studies using a shorter timeframe (one or three months) $(7,8)$. We did not distinguish between cancer and noncancer pain, and in doing so, we may have increased the prevalence slightly. In two previous studies using the same database, one excluded noncancer pain and reported a prevalence of $14 \%$ and the other did not exclude noncancer pain and reported a prevalence of $15.1 \%(14,29)$. Another limitation of the present study is that the findings can only be generalized to adults 25 years of age or older. However, this decision was based on several factors including the ability to compare our findings with other studies that used the same age cut-off $(2,7,8,29,31)$. In addition, adults younger than 25 years of age are more likely to be in the transition phase between living in the parental home and living independently, which may influence their sociodemographic characteristics, making them less comparable with adults 25 years of age or older. The findings are also limited to individuals not living in institutions, in the military, on Indian reserves and in some remote areas of Canada or the Territories. We hypothesize that our findings may be a conservative estimate of the true population prevalence.

\section{REFERENCES}

1. Andersson HI, Ejlertsson G, Leden I, Rosenberg C. Chronic pain in a geographically defined general population: Studies of differences in age, gender, social class, and pain localization. Clin J Pain 1993;9:174-82.

2. Elliott AM, Smith BH, Penny KI, Smith WC, Chambers WA. The epidemiology of chronic pain in the community. Lancet 1999;354:1248-52.

3. Millar WJ. Chronic pain. Health Reports. 1996; 7(4):47-53. <www. statcan.gc.ca/studies-etudes/82-003/archive/1996/5018989-eng.pdf> (Accessed March 29, 2012).

4. Turk DC. Clinical effectiveness and cost-effectiveness of treatments for patients with chronic pain. Clin J Pain 2002;18:355-65.

5. Kopec JA, Sayre EC. Work-related psychosocial factors and chronic pain: A prospective cohort study in Canadian workers. J Occup Environ Med 2004;46:1263-71.

6. Eriksen J, Ekholm O, SjØgren P, Rasmussen NK. Development of and recovery from long-term pain. A 6-year follow-up study of a cross-section of the adult Danish population. Pain 2004;108:154-62.

7. Magni G, Marchetti M, Moreschi C, Merskey H, Luchini SR. Chronic musculoskeletal pain and depressive symptoms in the National Health and Nutrition Examination. I. Epidemiologic follow-up study. Pain 1993;53:163-8.

8. Elliott AM, Smith BH, Hannaford PC, Smith WC, Chambers WA. The course of chronic pain in the community: Results of a 4-year follow-up study. Pain 2002;99:299-307

9. Blyth FM, March LM, Brnabic AJ, Jorm LR, Williamson M, Cousins MJ. Chronic pain in Australia: A prevalence study. Pain 2001;89:127-34.

10. Crook J, Rideout E, Browne G. The prevalence of pain complaints in a general population. Pain 1984;18:299-314.
Strengths of the present study include that it is the first prospective study conducted on a representative sample of the general population of Canada (with the exception of the limitations listed above); furthermore, it is the largest international prospective study examining sociodemographic predictors of chronic pain in the general population. Participants consisted of a random sample of the Canadian population and consistent, well-developed survey methodology was used over the 12-year study period (23). Nonresponses were accounted for by weighting the sample to the total population (24). Furthermore, response rates were high, and ranged from $83.6 \%$ in the first cycle to $77.0 \%$ in the final cycle $(23)$, with our response rates being comparable with previous prospective studies (67\% to $83 \%$ ) (6-8). Finally, the present study was the first to compare the prevalence and incidence of chronic pain over an extended period of time in the Canadian population, and to examine men and women separately.

The present study has implications at the health services level in terms of profiling communities or practices where additional resources may be required to address chronic pain. At the clinical level, health care professionals could target high-risk groups to provide appropriate management and treatment options to prevent or alleviate chronic pain.

ACKNOWLEDGEMENTS: The authors thank Dr Casey Warman for his help with statistical analyses at the Research Data Centre.

DISCLOSURES: Financial support was provided by the Freda Paltiel Award and a Queen's Graduate Award. There are no conflicts of interest with this research.

The abstract has been published in the International Association for the Study of Pain (IASP) conference book and online. These data have been previously presented at the Canadian Society for Epidemiology and Biostatistics student conference in Kingston, Ontario (May 2010), the IASP World Congress held in Montreal, Quebec (August 2010) and the Innovations in Gender, Sex, and Health Research in Toronto, Ontario (November 2010). We are not aware of any conflicts of interest with this research.

11. Eriksen J, Jensen MK, SjØgren P, Ekholm O, Rasmussen NK. Epidemiology of chronic non-malignant pain in Denmark. Pain 2003;106:221-8.

12. Moulin DE, Clark AJ, Speechley M, Morley-Forster PK. Chronic pain in Canada - Prevalence, treatment, impact and the role of opioid analgesia. Pain Res Manag 2002;7:179-84.

13. Ng KFJ, Tsui SL, Chan WS. Prevalence of common chronic pain in Hong Kong adults. Clin J Pain 2002;18:275-81.

14. Rashiq S, Dick BD. Factors associated with chronic noncancer pain in the Canadian population. Pain Res Manag 2009;14:454-60.

15. RustØen T, Wahl AK, Hanestad BR, Lerdal A, Paul S, Miaskowski C. Prevalence and characteristics of chronic pain in the general Norwegian population. Eur J Pain 2004;8:555-65.

16. SjØgren P, Ekholm O, Peuckmann V, Gronbaek M. Epidemiology of chronic pain in Denmark: An update. Eur J Pain 2009;13:287-92.

17. Von Korff M, Dworkin SF, Le Resche L. Graded chronic pain status: An epidemiologic evaluation. Pain 1990;40:279-91.

18. Sá K, Baptista AF, Matos MA, Lessa I. Prevalence of chronic pain and associated factors in the population of Salvador, Bahia. Rev Saude Publica. 2009;43:622-630. < www.scielosp.org/pdf/rsp/ v43n4/en_205.pdf> (Accessed March 29, 2012).

19. Fillingim RB, King CD, Ribeiro-Dasilva MC, Rahim-Williams B, Riley JL, III. Sex, gender, and pain: A review of recent clinical and experimental findings. J Pain 2009;10:447-85.

20. Ratzan SC, Filerman GL, LeSar JW. Attaining global health: Challenges and opportunities. Popul Bull 2000;55:1-48. <www.prb.org/

Source/55.1AttainGlobHealth_Eng.pdf.> (Accessed March 29, 2012).

21. Statistics Canada. National Population Health Survey - Household Component - Cross-sectional (NPHS), 2000. <www.statcan.gc.ca/ cgi-bin/imdb/p2SV.pl?Function=getSurvey\&SDDS=3236\&lang=en $\& d b=i m d b \& a d m=8 \&$ dis $=2>$ (Accessed March 29, 2012). 
22. Tambay JL, Catlin G. Sample design of the national population health survey. Health Rep 1995;7:29-38. <www.statcan.gc.ca/studiesetudes/82-003/archive/1995/5022568-eng.pdf> (Accessed March 29, 2012).

23. Statistics Canada. National Population Health Survey Household Component - Longitudinal (NPHS), 2008. $<$ www.statcan.gc.ca/cgi-bin/imdb/p2SV.pl?Function=getSurvey\&S DDS $=3225 \&$ lang $=$ en $\& d b=$ imdb $\&$ adm $=8 \&$ dis $=2>$ (Accessed March 29, 2012).

24. Statistics Canada. Statistics Canada National Population Health Survey Household Component Cycle 1 to 7 (1994/1995 to 2006/2007) Longitudinal Documentation, 2008. <www.statcan.gc. ca/imdb-bmdi/document/3225_D5_T1_V4-eng.pdf> (Accessed March 29, 2012).

25. Last JM. A Dictionary of Epidemiology, 2nd edn. New York: Oxford University Press, 1988

26. Statistics Canada. National Population Health Survey - Household Component - Cycle 7 (2006/2007), 2008. <www.statcan.gc.ca/ imdb-bmdi/instrument/3225_Q1_V7-eng.pdf> (Accessed March 29, 2012).

27. Health Surveillance Alberta Health. Chronic pain in Alberta: A portrait from the 1996 National Population Health Survey and the 2001 Canadian Community Health Survey, 2003. <www.health. alberta.ca/documents/Chronic-Pain-Survey-2003.pdf> (Accessed March 29, 2012).

28. Statistics Canada. National Population Health Survey: Health Institutions Component, Longitudinal (NPHS), $2000<w w w$. statcan.gc.ca/cgi-bin/imdb/p2SV.pl?Function $=$ getSurvey $\&$ SurvId $=1$ $9819 \&$ SurvVer $=1 \&$ InstaId $=20083 \&$ InstaVer $=2 \&$ SDDS $=5003 \&$ lan $\mathrm{g}=\mathrm{en} \& \mathrm{db}=\mathrm{IMDB} \& \mathrm{adm}=8 \& \mathrm{dis}=2>$ (Accessed March 29, 2012).

29. Van Den Kerkhof EG, Hopman WM, Towheed TE, Anastassiades TP, Goldstein DH, Canadian Multicentre Osteoporosis Study Research Group, Canada. The impact of sampling and measurement on the prevalence of self-reported pain in Canada. Pain Res Manag 2003;8:157-63.

30. Sá KN, Baptista AF, Matos MA, Lessa Í. Chronic pain and gender in Salvador population, Brazil. Pain 2008;139:498-506.

31. Reitsma M, Tranmer J, Buchanan D, VanDenKerkhof E. The prevalence of chronic pain in the Canadian population from 1994 to 2008. Chronic Dis Can 2011;31:157-64.

32. VanDenKerkhof EG, Macdonald HM, Jones GT, Power C, Macfarlane GJ. Diet, lifestyle and chronic widespread pain: Results from the 1958 British Birth Cohort Study. Pain Res Manage 2011;16:87-92. 


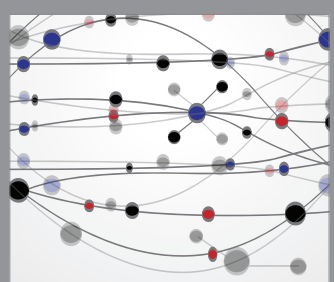

The Scientific World Journal
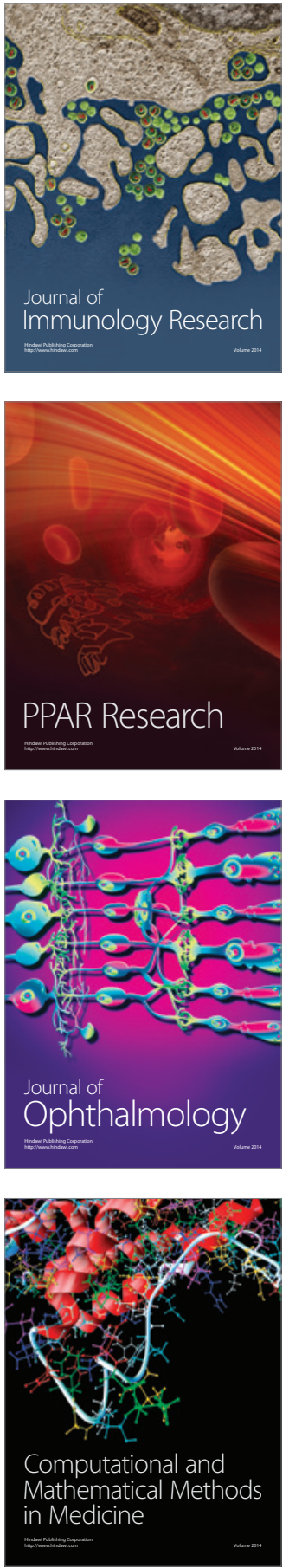

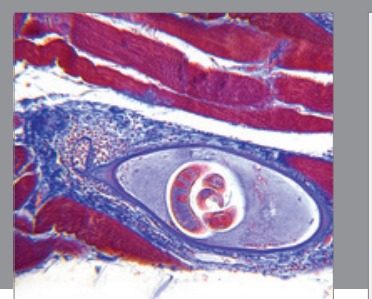

Gastroenterology Research and Practice

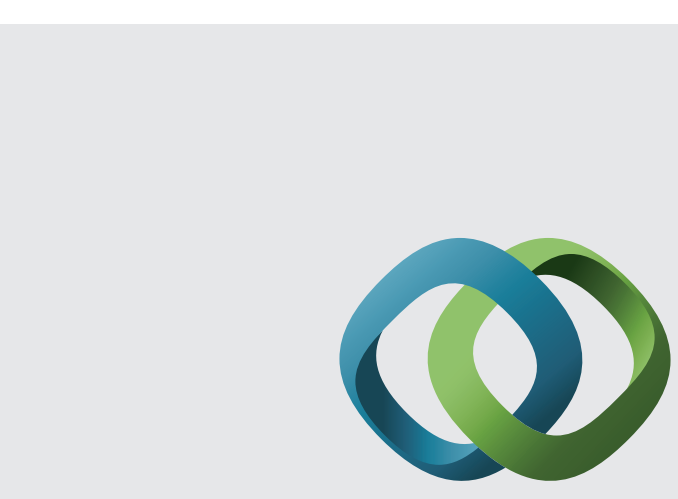

\section{Hindawi}

Submit your manuscripts at

http://www.hindawi.com
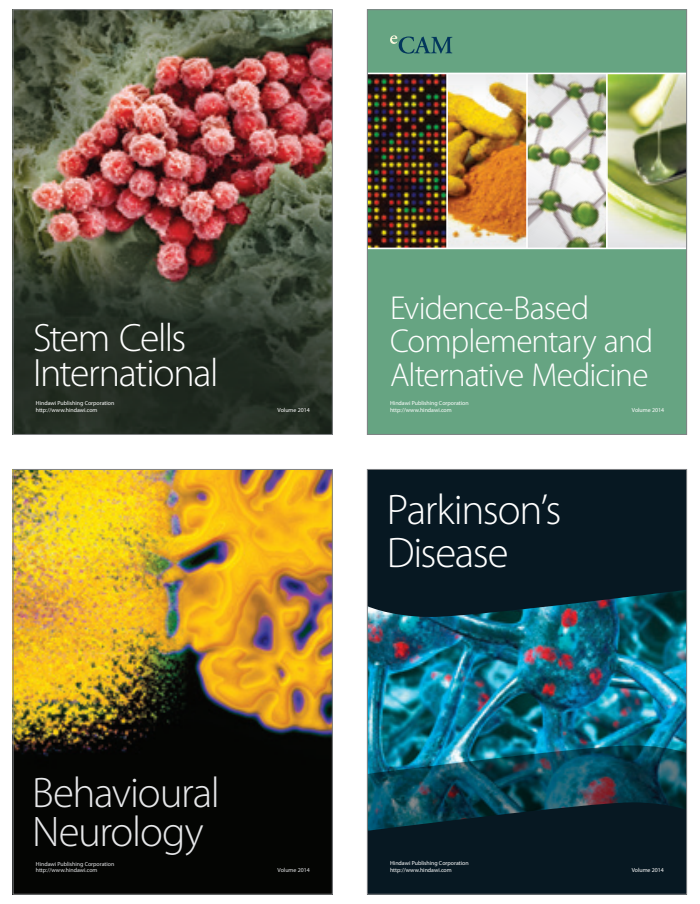
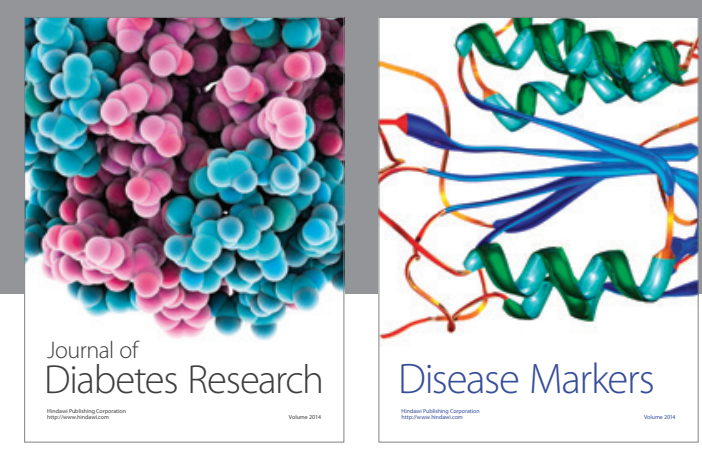

Disease Markers
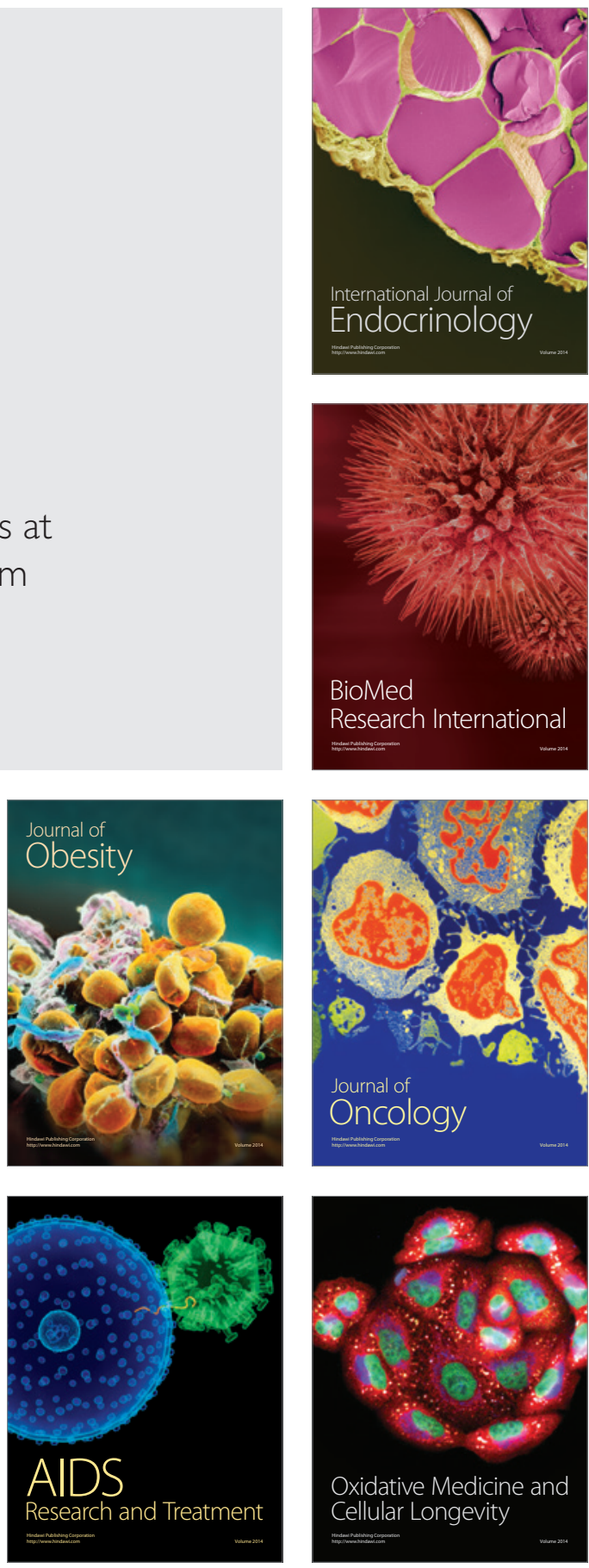